\title{
NATURALEZA Y CIUDAD. PERSPECTIVAS PARA LA ORDENACIÓN DE LA INFRAESTRUCTURA VERDE EN LOS PLANES TERRITORIALES METROPOLITANOS EN ESPAÑA
}

\author{
José María Feria Toribio \\ Departamento de Geografía, Historia y Filosofía. Universidad Pablo de Olavide \\ jmfertor@upo.es \\ Jesús Santiago Ramos \\ Departamento de Geografía, Historia y Filosofía. Universidad Pablo de Olavide \\ jsanram@upo.es
}

\section{RESUMEN}

La infraestructura verde se está asentando en los últimos años como una herramienta clave para la planificación del espacio libre metropolitano desde una perspectiva estratégica y multifuncional. Ante la gran diversidad de aproximaciones teóricas y aplicadas a este concepto que coexisten en la actualidad, el presente trabajo plantea como objetivos abordar una revisión crítica del mismo y explorar sus posibilidades de implementación a través de la planificación territorial a escala metropolitana, para lo cual se realiza un análisis comparado de los planes de Barcelona, Bilbao y Sevilla.

Palabras clave: Infraestructura verde, Áreas metropolitanas, Ordenación del Territorio.

\section{ABSTRACT}

In recent years, green infrastructure has become a key tool for planning metropolitan natural areas and environmental features from a strategic and multifunctional perspective. Given the great diversity of theoretical and applied approaches currently being adopted for the analysis and design of green infrastructures, this paper addresses a critical review of

Fecha de recepción: septiembre 2015.

Fecha de aceptación: diciembre 2016. 
this concept and explores its potential implementation through metropolitan-scale spatial plans. To this end, the article presents a comparative analysis of the three main Spanish metropolitan plans -Barcelona, Bilbao and Seville.

Keywords: Green infrastructure, Metropolitan areas, Spatial planning.

\section{INTRODUCCIÓN}

En el momento actual existe un consenso generalizado en los ámbitos académico, institucional y técnico acerca del importante papel que juegan los elementos naturales y los espacios no construidos como componentes estructurales y funcionales de los sistemas urbanos. Su valor como elementos vertebradores del territorio y su potencialidad para ofrecer un amplio abanico de funciones sociales y ambientales los convierten en un recurso estratégico indispensable para cualquier iniciativa de planificación orientada según los principios de un desarrollo urbano sostenible y equilibrado. La presencia de lo natural en el seno de un espacio tan intensamente antropizado como es la ciudad supone una garantía para la provisión de numerosos servicios ecosistémicos, que redundan en una mejora de la calidad ambiental urbana (Bolund y Hunhammar, 1999). Frente a la visión urbanística más tradicional, que a veces ha tendido a considerar a la ciudad y la naturaleza como elementos opuestos y excluyentes, esta nueva aproximación representa un claro cambio de perspectiva marcado por la búsqueda de un equilibrio entre los componentes artificiales y naturales del sistema territorial urbano. Uno de los conceptos que mejor representa actualmente este cambio de paradigma, tanto por su amplia difusión como por su rápida adopción por parte de instituciones y organismos oficiales, es el de infraestructura verde.

En términos generales, la infraestructura verde supone una nueva perspectiva de ordenación de los espacios libres y los elementos naturales, que asume como principios esenciales la interconexión en red de los componentes de valor ambiental de un territorio, la potenciación de su multifuncionalidad y la adopción de un enfoque "inteligente" (smart) y proactivo en su planificación y gestión (AEMA, 2011). Se trata de un concepto que puede ser implementado a diferentes escalas -desde la local a la regional o la nacional- y con distintos fines específicos -desde la protección de los hábitats naturales más valiosos al fomento de determinados servicios ecosistémicos o la potenciación del desarrollo local. En el contexto de la planificación territorial, la infraestructura verde muestra un singular interés como mecanismo para contrarrestar los impactos derivados de los procesos de crecimiento urbano difuso o urban sprawl (Benedict y McMahon, 2002). Dada la creciente dimensión de este fenómeno, y siendo cada vez más conocidas las consecuencias del mismo tanto sobre el medio natural como sobre la propia calidad ambiental de los entornos urbanos, parece más que justificado profundizar en los beneficios que puede aportar la infraestructura verdeen el contexto de las grandes áreas urbanas, así como evaluar los posibles mecanismos y herramientas para su correcta implementación.

Para responder a este objetivo, se hace necesario adoptar una escala adecuada de análisis e intervención. En este sentido, es importante entender que, en el momento actual, la escala de los procesos que determinan el funcionamiento y la configuración espacial de los 
sistemas urbanos supera ampliamente el ámbito de lo municipal. En las últimas décadas, el potente incremento de la movilidad urbana, unido a otros factores ligados sobre todo a las nuevas formas de desarrollo residencial, ha contribuido al desbordamiento definitivo de los límites de la ciudad tradicional, generando un ámbito funcional más extenso y complejo que denominamos como metropolitano (Hall, 1998). En consonancia con esta nueva realidad, es aconsejable la asunción de una escala más amplia que la estrictamente local para lograr una correcta comprensión, planificación y gestión de los sistemas urbanos (Feria, 2004),con un redimensionamiento de las estrategias de estudio e intervención, que ya viene siendo adoptado desde hace tiempo por diferentes instituciones y organismos de referencia (OECD, 2012).

Siguiendo esta línea de reflexión, el presente estudio sostiene como hipótesis de trabajo que los planes territoriales de escala metropolitana constituyen una herramienta adecuada para una óptima implementación del concepto de infraestructura verde en las grandes áreas urbanas. A diferencia de otros instrumentos de intervención de carácter sectorial, los planes metropolitanos permiten abordar de forma conjunta e integrada la ordenación de los dos componentes esenciales del territorio urbano -el espacio construido y el espacio libre-, lo cual no solo debería permitir una mejor protección de los recursos naturales y ambientales locales frente a los procesos de expansión urbana, sino también potenciar una configuración espacial de los sistemas verdes capaz de maximizar sus beneficios ambientales y sociales. A partir de esta hipótesis, el artículo se plantea un doble objetivo: en primer lugar, realizar una revisión crítica de la noción de infraestructura verde, orientada fundamentalmente a su implementación en un contexto metropolitano; y en segundo lugar, evaluar la potencial aplicación del concepto a través de los instrumentos de ordenación territorial de escala metropolitana, desarrollando para ello un análisis comparado de tres documentos de ordenación actualmente en vigor. Los planes seleccionados para este fin corresponden a las tres principales áreas metropolitanas españolas que cuentan actualmente con instrumentos de esta naturaleza: Barcelona, Bilbao y Sevilla. Se trata de planes relativamente recientes que, a pesar de coincidir en su naturaleza supramunicipal, presentan diferencias significativas tanto en lo relativo al enfoque de ordenación como en cuanto a la realidad territorial sobre la que inciden. Por ello, en su conjunto ofrecen un innegable interés para explorar diferentes aproximaciones al tratamiento de esta cuestión en la escala metropolitana.

Con objeto de dar cumplimiento a los objetivos, los contenidos del trabajo se estructuran en cinco partes. En la primera de ellas se lleva a cabo una aproximación general a la definición del concepto de infraestructura verde y a la identificación de sus principales rasgos formales y funcionales ${ }^{1}$. La segunda profundiza en las implicaciones de la adopción de una escala metropolitana para la aplicación del concepto, tomando en consideración las particularidades que representa esta escala en relación a otras aproximaciones de carácter local o regional, y tratando de acotar tanto los componentes como las funciones específicas que pueden asociarse a la infraestructura verde en este contexto. A continuación, se aborda la caracterización general de los planes seleccionados para el estudio y una aproximación sintética de sus contenidos en relación al objeto de la investigación, analizando el tratamiento que en ellos se desarrolla de los componentes y funciones habitualmente asociados a la noción de

1 Un tratamiento algo más detallado de esta cuestión puede encontrarse en Feria y Santiago, 2016. 
infraestructura verde. El cuarto apartado presenta una discusión de los resultados del análisis a la luz de los rasgos esenciales de la infraestructura verde identificados en la revisión conceptual: conectividad, multifuncionalidad y enfoque proactivo de ordenación. Finalmente, y a modo de conclusión, se plantea una reflexión sobre la idoneidad de la ordenación territorial como herramienta para la constitución de infraestructuras verdes, atendiendo tanto a las limitaciones y carencias detectadas en los documentos de planificación analizados, como a las potencialidades y avances que podrían consolidarse en una futura generación de planes metropolitanos.

\section{APROXIMACIÓN AL ORIGEN Y LA DEFINICIÓN DEL CONCEPTO DE INFRAESTRUCTURA VERDE}

Aunque el origen del concepto de infraestructura verde puede situarse en Estados Unidos en la década de los años 90, donde surge como respuesta a la creciente preocupación por las implicaciones ambientales del fenómeno del urban sprawl, sus presupuestos teóricos se asientan sobre algunos planteamientos de larga tradición en el campo del urbanismo y la planificación territorial. Por ejemplo, se podrían citar como antecedentes la creación de redes interconectadas de parques urbanos y periurbanos, que se remontarían hasta las propuestas de Frederick Law Olmsted para Nueva York a mediados del siglo XIX (Soria, 1997); el desarrollo de greenways y redes ecológicas tanto para el uso público como para la conservación ambiental (Ahern, 1995; Jongman et al., 2004, Opdam et al., 2005); y en general toda una línea de reflexión que, desde el ámbito del urbanismo, viene abogando desde principios del siglo XX por una articulación más armónica de la ciudad con su entorno rural y natural (Geddes, 1915; Mumford, 1956; McHarg, 1969; Bettini, 1998). El concepto de infraestructura verde recoge y actualiza este conjunto de ideas y referentes, proponiendo un enfoque estratégico de actuación adaptado a los retos de la ciudad actual, y situando la conexión física y funcional entre zonas verdes, espacios abiertos y áreas naturales como eje prioritario de intervención sobre el territorio urbanizado. La elección del término "infraestructura" no sólo viene a reflejar esta visión del espacio no construido como un sistema de espacios interconectados, sino que supone ante todo una reivindicación de su papel como elemento articulador del sistema urbano (AEMA, 2015). La infraestructura verde se contrapone así a la noción de "infraestructura gris" (es decir, el conjunto de infraestructuras de carácter artificial), en un intento de equiparar la importancia de ambos componentes del sistema territorial y de superar el carácter subordinado y residual que a menudo asume la ordenación del espacio no urbanizado frente al resto de usos del territorio. Desde esta perspectiva, la noción de infraestructura verde estaría estrechamente vinculada a la aproximación sistémica y territorial al concepto de espacio libre que desarrollan algunos autores (Folch, ed. 2003), y que ha comenzado a ser adoptada recientemente en el ámbito de la planificación (Feria y Santiago, 2009).

A pesar de su corta existencia, el concepto de infraestructura verde ha experimentado desde su aparición un rápido proceso de difusión, observándose sobre todo en los últimos años un interés progresivo por el mismo en el ámbito internacional. En el momento actual es posible encontrarlo ligado a muy diferentes iniciativas y propuestas tanto de análisis como de planificación en todo el mundo (AEMA, 2011; Elmqvist et al., 2013). Dentro de este contexto, destaca de forma particular el caso de Europa, donde la noción de infraestructura 
verde ha sido adoptada por las instituciones de la Unión Europea como una herramienta estratégica en el marco de las políticas de cohesión territorial, conservación de la naturaleza y fomento de la sostenibilidad urbana. En este sentido, la Comisión Europea ha desarrollado una Estrategia sobre Infraestructura Verde bajo el título "Mejorando el capital natural de Europa" (Comisión Europea, 2013), que está en consonancia con la progresiva integración del concepto en acciones y programas comunitarios tales como el Séptimo Programa Marco de Medio Ambiente (2013), la Estrategia de Biodiversidad Europea (2011) o la Estrategia de la Unión Europea para el Cambio Climático (2013).En el contexto español se observa también un proceso de asimilación de este concepto en iniciativas de diferente escala y naturaleza. Como ejemplos significativos, se puede citar el Plan de Acción Territorial de Infraestructura Verde y Paisaje de la Comunitat Valenciana (2011), la propuesta de infraestructura verde a escala municipal para Vitoria-Gasteiz (2015), la incorporación del concepto en el Plan Insular de Gran Canaria (2014), o su integración en el marco de la legislación forestal (Ley 21/2015 de Montes).

La adaptación del concepto a contextos geográficos y escalas de intervención muy diferentes ha derivado en la aparición de una gran diversidad de acepciones y enfoques de aplicación. A día de hoy podría decirse que la noción de infraestructura verde ha llegado a convertirse en una especie de "concepto-paraguas" bajo el que se recogen experiencias de distinto alcance y orientación: desde la creación de redes regionales, nacionales o supranacionales para la conservación de los hábitats naturales (como la Red Natura 2000 en Europa), al desarrollo de anillos y redes verdes multifuncionales en entornos urbanos y periurbanos (como pueden ser los casos de Vitoria-Gasteiz, en España, o Cambridge, en el Reino Unido), o el diseño de sistemas de drenaje natural a escala local (un enfoque asumido por ejemplo por la US Environmental Protection Agency o el Plan de Infraestructura Verde de Nueva York). Como consecuencia, no existe en la actualidad una definición de consenso que sea unánimemente aceptada y que pueda ajustarse de forma satisfactoria a la casuística tan diversa que rodea al diseño e implementación de estas estructuras (AEMA, 2011). Dentro del amplio abanico de definiciones en uso, cabe destacar algunas aproximaciones que resultarían de especial utilidad en el contexto de la ordenación territorial en ámbitos metropolitanos. Una de ellas sería la aportada por el organismo público Natural England, que define la infraestructura verde "como una red de espacios verdes y otros elementos naturales de alto valor, planificada y desarrollada desde una perspectiva estratégica. Debe ser diseñada y gestionada como un recurso multifuncional capaz de proporcionar un amplio espectro de beneficios ambientales y ligados a la calidad de vida de las comunidades locales" (Natural England, 2010). Por su parte, el Plan de Infraestructura Verde de la Comunitat Valenciana ofrece una definición centrada en su composición y configuración física; desde esta óptica, la infraestructura verde es la "estructura territorial básica formada por las áreas y los elementos territoriales de alto valor ambiental, cultural y visual, por las áreas críticas del territorio que deben quedar libres de urbanización, y por el entramado de corredores ecológicos y conectores funcionales que ponen en relación los elementos anteriores" (Generalitat Valenciana, 2011, pág. 9). Una tercera perspectiva, de carácter más general, sería la identificación de la 
infraestructura verde con la matriz del territorio, pudiendo definirse como el "sistema de soporte vital de la región"2 que actúa como sostén físico y funcional para el resto de usos.

A pesar del notable grado de dispersión existente en el plano conceptual, es posible identificar tres rasgos esenciales que resultan comunes a la mayoría de las definiciones (AEMA, 2011). El primero de estos rasgos es la búsqueda de un alto nivel de conectividad entre los espacios que componen la infraestructura, a fin de conseguir su completa integración tanto en el plano estructural como en el funcional. Desde un punto de vista ecológico, este enfoque coincide plenamente con los planteamientos de la ecología del paisaje (Forman y Godron, 1986), según los cuales una mayor conectividad favorece la conservación de los hábitats naturales, al contrarrestar los efectos nocivos que procesos como la fragmentación del paisaje y el progresivo aislamiento de los hábitats naturales tienen sobre la biodiversidad (Forman, 2008). Por otro lado, desde la perspectiva del uso público, un aumento de la conectividad basado en el diseño o la recuperación de vías verdes, senderos o caminos rurales tiene un impacto positivo sobre la movilidad sostenible en entornos urbanos o periurbanos, al facilitar los desplazamientos no motorizados (a pie o en bicicleta) entre las zonas dedicadas a actividades de ocio al aire libre (Santiago, 2008). Por último, en lo que respecta a la planificación y gestión del territorio, la articulación en red de los espacios no urbanizados facilita su entendimiento como un sistema unitario, favoreciendo estrategias de intervención de carácter integrador (Opdam et al., 2005).

Un segundo rasgo esencial de las infraestructuras verdes sería su vocación abiertamente multifuncional. De forma general, el concepto de multifuncionalidad se refiere a la integración de las diferentes facetas funcionales de un mismo sistema territorial, ya sean ambientales, sociales o productivas (OECD, 2001; Mander et al., 2007). Cada componente de la infraestructura verde es capaz de aportar una serie de funciones o servicios específicos acordes con su naturaleza, su grado de antropización, su localización y sus dimensiones. Dado que el número de servicios que puede aportar un determinado espacio suele ser limitado, la multifuncionalidad se considera como un objetivo a escala de conjunto o de sistema (Landscape Institute, 2009). Lo que se persigue por tanto es maximizar la suma total de beneficios que es posible extraer de la infraestructura verde, un objetivo que requiere forzar las complementariedades y sinergias que existen entre los diferentes componentes del sistema.

Por último, el tercer rasgo característico de las infraestructuras verdes sería la adopción de un enfoque estratégico para su planificación y gestión. En otras palabras, se trata de asumir una perspectiva de conservación activa, ligada a la puesta en valor de los recursos de forma compatible con la preservación de sus cualidades, dentro de lo que se vendría a denominar un planteamiento de smart conservation (Benedict y McMahon, 2002). Aparte de fomentar la provisión de servicios ecosistémicos, este enfoque tendría como finalidad adicional contribuir a la dinamización socioeconómica de los ámbitos sometidos a ordenación y promover el desarrollo local a través de la puesta en valor del patrimonio territorial (Feria, 2012). Todo ello conlleva un cambio de gran calado frente a los enfoques tradicionales de conservación, de carácter reactivo en lugar de proactivo, y restringidos esencialmente a la limitación y regulación de usos sobre determinados elementos del territorio.

2 Glosario de Green Infrastructure NW: www.greeninfrastructurenw.co.uk [página consultada el 18/01/2016]. 
La vocación aplicada del concepto y su naturaleza estratégica lo convierten en una herramienta muy valiosa para conectarlos ámbitos académico, técnico e institucional, abriendo una vía directa para la aplicación práctica del conocimiento científico a través de propuestas concretas de intervención sobre el territorio. Al mismo tiempo, su carácter marcadamente transdisciplinar -ligado a la idea de multifuncionalidad- favorece su adopción por parte de las diversas disciplinas científicas y campos de conocimiento que se ocupan de la componente ambiental y paisajística de los sistemas territoriales, utilizándose de forma cada vez más habitual en trabajos vinculados a la conservación de la biodiversidad (Wickham et al., 2010), la gestión de los procesos hidrológicos en entornos urbanizados (Jia et al., 2016), el análisis de la dimensión social de la configuración del verde urbano (Heckert y Rosan, 2016), o la valoración económica de los servicios ecosistémicos (Myles, 2015), por citar algunos ejemplos. En la medida en que la infraestructura verde tiende a consolidarse como "concepto-puente" entre diferentes campos de conocimiento y entre los ámbitos científico y técnico, parece conveniente acotar de forma más precisa ciertos extremos relativos a su naturaleza, su composición y su funcionalidad. Una excesiva indefinición en relación a estos aspectos no sólo supone un menoscabo del valor de este concepto como objeto o espacio común de trabajo, sino que también abre la puerta a un potencial proceso de banalización, sobre todo en lo que respecta a su traslación al plano aplicado. En particular, en el ámbito de la planificación territorial, resulta prioritario definir qué recursos territoriales se consideran parte de la infraestructura verde, cuáles son los beneficios específicos que se le asocian y cuáles son las estrategias más adecuadas para su efectiva implementación. Dado que estos aspectos dependen en gran medida de la escala de ordenación (Comisión Europea, 2013), parece necesario atender a este factor en aras de una mayor concreción, sobre todo en relación a los condicionantes específicos de su aplicación en entornos metropolitanos.

\section{LA APLICACIÓN DEL CONCEPTO DE INFRAESTRUCTURA VERDE A LA ESCALA METRO- POLITANA}

La Agencia Europea del Medio Ambiente propone una clasificación de las infraestructuras verdes en dos categorías en función de su escala (AEMA, 2011): de un lado se sitúan las infraestructuras verdes de escala amplia, de carácter regional o nacional, vinculadas en su mayor parte a los grandes sistemas interconectados de protección de la naturaleza; de otro, las infraestructuras verdes de escala local, ligadas fundamentalmente a la ordenación de espacios libres y áreas verdes en el contexto de una ciudad o de un barrio. Cada una de estas escalas correspondería a una orientación o finalidad específica. Las infraestructuras verdes planificadas a una escala regional o nacional tienen como objeto fundamental la conservación de los ecosistemas naturales más valiosos y los procesos ecológicos que los sustentan. En contraste, las infraestructuras verdes de carácter local se orientan en mayor medida a la mejora de la calidad ambiental de un entorno concreto, ya sea priorizando una función específica (p. ej. la regulación hidrológica) o fomentando la provisión simultánea de diferentes servicios ecosistémicos. Consecuentemente, la tipología de elementos potencialmente asociados a una y otra escala también muestra diferencias notables.

La articulación de una infraestructura verde de dimensión metropolitana vendría a representar una tercera categoría dentro de esta clasificación. Se trata de una escala intermedia, de 
carácter subregional, que permite integrar en una sola propuesta las funciones y componentes asociados a cada una de las dos escalas anteriores, y que hace posible abordar desde una perspectiva unitaria el conjunto del sistema urbano y el medio rural y natural en el que éste se inserta. Esta aproximación enlaza con la visión, ya ampliamente asumida tanto en el plano académico como en el institucional, de que las dinámicas y procesos formales y funcionales asociados en el momento actual al fenómeno urbano superan claramente los límites de la ciudad tradicional. La adopción de una escala metropolitana para el diseño y ordenación de una infraestructura verde supone en última instancia una adaptación de este concepto a la compleja y dinámica realidad territorial que surge del redimensionamiento de los sistemas urbanos. Una realidad que condiciona tanto la composición y configuración física de estas estructuras verdes como su dimensión funcional.

En relación al primero de estos aspectos, la escala metropolitana es lo suficientemente amplia como para permitir la integración en red de un conjunto muy diverso de espacios y recursos territoriales de diferente naturaleza y entidad, que abarcarían desde las zonas verdes presentes en el tejido urbano hasta las grandes áreas de carácter natural o rural más alejadas de la ciudad. En este contexto adquieren un especial valor aquellos elementos que por su carácter lineal son adecuados para garantizar un alto grado de conectividad entre los componentes de la infraestructura. En particular, destacarían para tal fin la red fluvial y la red de caminos rurales presentes en el entorno de las ciudades, recursos que en muchos casos se encuentran vinculados al dominio público, lo que facilita su ordenación y gestión. La Tabla 1 muestra el listado de recursos potenciales para la articulación de una infraestructura verde metropolitana. Este catálogo de componentes permite abarcar la práctica totalidad del espacio no construido (la matriz o soporte territorial del espacio metropolitano), con independencia de la titularidad o el tipo de uso particular de cada elemento. La suma de los recursos recogidos en la tabla permite la articulación de un gradiente urbano-rural-natural desde el centro del sistema metropolitano hacia la periferia, en la que a cada elemento le corresponde un papel y un grado de protección específicos en función de su naturaleza y su localización (Hough, 1998).

Desde el punto de vista de la funcionalidad, la gran diversidad de elementos que pueden ser incorporados a la infraestructura verde a escala metropolitana hace posible la provisión simultánea de un amplio espectro de servicios ecosistémicos. La Tabla 2 muestra un listado de los servicios o funciones más relevantes. En términos generales, los servicios ofrecidos por la infraestructura verde se vincularían con tres dimensiones esenciales del proyecto urbano sostenible. Por un lado, el incremento de la calidad ambiental en el espacio urbanizado, actuando estos sistemas como un recurso estratégico para la mejora de la calidad del aire (Manes et al., 2014, Fusaro et al., 2015; Kim et al., 2015), la gestión sostenible y eficiente de los procesos hidrológicos (Lewellyn et al., 2016) o la mitigación de la isla de calor urbano (Farrugia et al., 2013). En segundo lugar, y desde una perspectiva más global, la infraestructura verde se convertiría en un factor estratégico para dotar a las ciudades de una mayor resiliencia, sobre todo a través de su contribución a la adaptación y la lucha contra el cambio climático (Momm-Schult et al., 2013) y de su papel en relación a la seguridad alimentaria y la producción de alimentos (Magoni y Colucci, 2015). Por último, la infraestructura verde metropolitana atiende también a la dimensión social y económica de la sostenibilidad, aportando beneficios intangibles de orden estético, cultural y recreativo (Chiesura, 
2004), contribuyendo a un ambiente más saludable para los ciudadanos (Tzoulas et al., 2007) y proporcionando funciones de carácter económico (Comisión Europea, 2013)vinculadas a la incorporación de espacios dedicados a la producción primaria y a la puesta en valor del patrimonio territorial local. La distribución espacial de estas funciones responde también a la idea de gradiente urbano-rural: algunos de los servicios señalados estarían ligados en mayor medida a los espacios libres localizados en el tejido urbano y su periferia inmediata, mientras que otros se vincularían fundamentalmente a los hábitats naturales más extensos y alejados de las presiones urbanas. Esta dualidad funcional refuerza el papel de la escala metropolitana como escala intermedia entre lo local y lo regional, un rasgo que permite dotar al sistema verde de un carácter multifuncional más completo que el esperable a otras escalas de ordenación.

Tabla 1

COMPONENTES POTENCIALES DE LA INFRAESTRUCTURA VERDE METROPOLITANA

\begin{tabular}{ll}
\hline Elementos extensivos & Elementos lineales y de conexión \\
\hline Espacios ligados al tejido urbano & Corredores ecológicos \\
\hline Parques periurbanos y metropolitanos & $\begin{array}{l}\text { Elementos de conexión para uso público } \\
\text { (senderos, carriles bici, etc.) }\end{array}$ \\
\hline Parques urbanos & Red fluvial \\
\hline $\begin{array}{l}\text { Otros espacios abiertos urbanos con } \\
\text { vegetación }\end{array}$ & Vías pecuarias y caminos rurales \\
\hline $\begin{array}{l}\text { Elementos arquitectónicos (fachadas y } \\
\text { cubiertas vegetales) }\end{array}$ & Elementos puntuales \\
\hline $\begin{array}{l}\text { Espacios naturales / forestales } \\
\text { Áreas naturales protegidas }\end{array}$ & $\begin{array}{l}\text { Elementos del patrimonio cultural (yacimientos, } \\
\text { haciendas...) }\end{array}$ \\
\hline $\begin{array}{l}\text { Zonas naturales y forestales sin } \\
\text { protección }\end{array}$ & $\begin{array}{l}\text { Otros elementos puntuales (áreas de descanso, } \\
\text { nodos de transporte...) }\end{array}$ \\
\hline $\begin{array}{l}\text { Zonas multifuncionales con valor } \\
\text { ambiental }\end{array}$ & \\
\hline Espacios agrarios & \\
\hline Huertos urbanos y periurbanos & \\
\hline Parques agrícolas & \\
\hline Usos agrícolas (con carácter extensivo)
\end{tabular}

Fuente: elaboración propia a partir de AEMA (2011).

Si bien muchas de las funciones recogidas en la Tabla 2 pueden ser asociadas indistintamente a las infraestructuras verdes de escala local o regional, existen otras que adquieren su verdadera significación exclusivamente dentro de un contexto de ordenación metropolitano. Tal es el caso de las funciones de carácter territorial o urbanístico, ligadas en esencia a la regulación del crecimiento de la ciudad. Una infraestructura verde diseñada a escala supramunicipal puede actuar como un instrumento para la contención del crecimiento urbano disperso, permitiendo reorientar los nuevos desarrollos urbanos a zonas más apropiadas 
desde el punto de vista de una valoración global de su idoneidad ambiental, generar zonas de transición entre los espacios más intensamente antropizados y las áreas más vulnerables, y contener los procesos de conurbación.

Tabla 2

FUNCIONES POTENCIALES DE LA INFRAESTRUCTURA VERDE METROPOLITANA

\begin{tabular}{lc}
\hline Funciones recreativas y de ocio & Funciones hidrológicas \\
\hline $\begin{array}{l}\text { Espacio para actividades } \\
\text { recreativas y deportivas }\end{array}$ & Protección de zonas inundables \\
\hline Contacto con la naturaleza & Drenaje y prevención de la escorrentía superficial \\
\hline $\begin{array}{l}\text { Otras actividades de } \\
\text { uso público (culturales, } \\
\text { educativas...) }\end{array}$ & Depuración del agua \\
\hline $\begin{array}{l}\text { Funciones relacionadas con la } \\
\text { biodiversidad }\end{array}$ & Funciones relacionadas con el espacio agrícola \\
\hline $\begin{array}{l}\text { Conservación de hábitats } \\
\text { naturales }\end{array}$ & Producción de alimentos y seguridad alimentaria \\
\hline $\begin{array}{l}\text { Desplazamiento de especies } \\
\text { (conectividad, permeabilidad) }\end{array}$ & Conservación del suelo productivo \\
\hline $\begin{array}{l}\text { Funciones relacionadas con la } \\
\text { calidad ambiental y la salud }\end{array}$ & Funciones territoriales / urbanísticas \\
\hline $\begin{array}{l}\text { Mitigación del cambio } \\
\text { climático (captación y retención } \\
\text { de CO })\end{array}$ & Regulación del crecimiento urbano y la conurbación \\
\hline $\begin{array}{l}\text { Mejora de la calidad del aire / } \\
\text { absorción de contaminantes }\end{array}$ & Fomento de la movilidad no motorizada \\
\hline $\begin{array}{l}\text { Regulación de la temperatura } \\
\text { urbana / isla de calor }\end{array}$ & Funciones relacionadas con el patrimonio cultural \\
\hline & Conservación del patrimonio histórico / cultural \\
\hline
\end{tabular}

Fuente: elaboración propia a partir de AEMA (2011) y Comisión Europea (2013).

Este papel activo de la infraestructura verde en relación a la articulación y configuración espacial del territorio metropolitano apuntaría a la necesidad de alcanzar una adecuada coordinación entre el diseño de estos sistemas verdes y la planificación del crecimiento urbano. Para ello se plantean dos posibilidades. La primera es el desarrollo de instrumentos específicos de ordenación para las infraestructuras verdes, que tengan un carácter vinculante sobre los instrumentos de ordenación de escala subregional y municipal. La segunda opción es incorporar el diseño de las infraestructuras verdes en el marco de los planes de ordenación de carácter integral, atribuyéndoles un peso relevante en el conjunto de la propuesta de ordenación, y situándolas como un componente más del modelo territorial desarrollado. Si se atiende a su dimensión estratégica, la infraestructura verde no constituye sólo el conjunto de espacios a preservar de la urbanización, sino que se trata ante todo de un componente activo, de carácter estructural, que requiere ser ordenado de forma coordinada con el resto de 
elementos del sistema urbano en el marco de un modelo de desarrollo territorial equilibrado y sostenible. Por ello, esta segunda posibilidad se ajusta mejor a la aproximación conceptual que se ha desarrollado hasta aquí.

\section{ANÁLISIS DE CASOS: COMPONENTES Y FUNCIONES DE LA INFRAESTRUCTURA VERDE EN TRES PLANES METROPOLITANOS ESPAÑOLES}

A tenor de la reflexión anterior, resulta necesario evaluar en qué medida los actuales instrumentos de planificación de las áreas metropolitanas constituyen un instrumento adecuado para la efectiva articulación de infraestructuras verdes que respondan a los principios formales y funcionales ya enunciados. Dado que estamos ante un concepto relativamente nuevo y poco utilizado hasta el momento en la práctica de la ordenación territorial a dicha escala, se trataría no de analizar la aplicación directa y explícita de dicho concepto en los planes, sino de explorar los contenidos y propuestas incluidos en ellos en relación a esta materia. De forma específica, el análisis comparado se centrará en el tratamiento que desde los planes metropolitanos se hace de los elementos y funciones habitualmente asociados a la infraestructura verde, y que han sido identificados en el apartado anterior.

Para atender tal propósito abordaremos los planes de ordenación territorial metropolitana correspondientes a tres de las más importantes áreas metropolitanas españolas. Como se ha puesto de manifiesto en otras investigaciones (Feria, Rubio y Santiago, 2005) la puesta en marcha de planes de ordenación territorial en España, sobre todo en ámbitos metropolitanos, no ha sido una prioridad de las políticas públicas hasta muy recientemente. Es solamente a partir de la primera década del presente siglo cuando empiezan a aprobarse un conjunto de planes metropolitanos que abordan la ordenación territorial de estos ámbitos. Entre ellos los que aquí trataremos y que son, por orden de aprobación, los de Bilbao (2006), Sevilla (2009) y Barcelona (2010); las áreas metropolitanas, respectivamente, quinta, cuarta y segunda de la jerarquía urbana española. Cabe resaltar que la primera, Madrid, y la tercera, Valencia, no han desarrollado, hasta el momento, ningún plan de ordenación territorial para sus respectivos ámbitos.

Tabla 3

DATOS BÁSICOS DE REFERENCIA DE LOS PLANES METROPOLITANOS

DE ORDENACIÓN TERRITORIAL ANALIZADOS

\begin{tabular}{llcccc}
\hline \multicolumn{1}{c}{ Área } & \multicolumn{1}{c}{ Denominación del Plan } & $\begin{array}{c}\text { Año de } \\
\text { aprobación }\end{array}$ & $\begin{array}{c}\text { Población } \\
\text { aprox. }\end{array}$ & $\begin{array}{c}\text { Núm. } \\
\text { municip. }\end{array}$ & $\begin{array}{c}\text { Superf. } \\
\left(\mathbf{k m}^{2}\right)\end{array}$ \\
\hline Barcelona & $\begin{array}{l}\text { Plan Territorial Metropolitano de } \\
\text { Barcelona }\end{array}$ & 2010 & 4.800 .000 & 164 & 3.236 \\
\hline Bilbao & $\begin{array}{l}\text { Plan Territorial Parcial de Bilbao } \\
\text { Metropolitano }\end{array}$ & 2006 & 900.000 & 35 & 505 \\
\hline \multirow{2}{*}{ Sevilla } & $\begin{array}{l}\text { Plan de Ordenación del Territorio } \\
\text { de la Aglomeración Urbana de } \\
\text { Sevilla }\end{array}$ & 2009 & 1.450 .000 & 46 & 4.900 \\
\hline
\end{tabular}

Fuente: elaboración propia a partir de los planes analizados. 


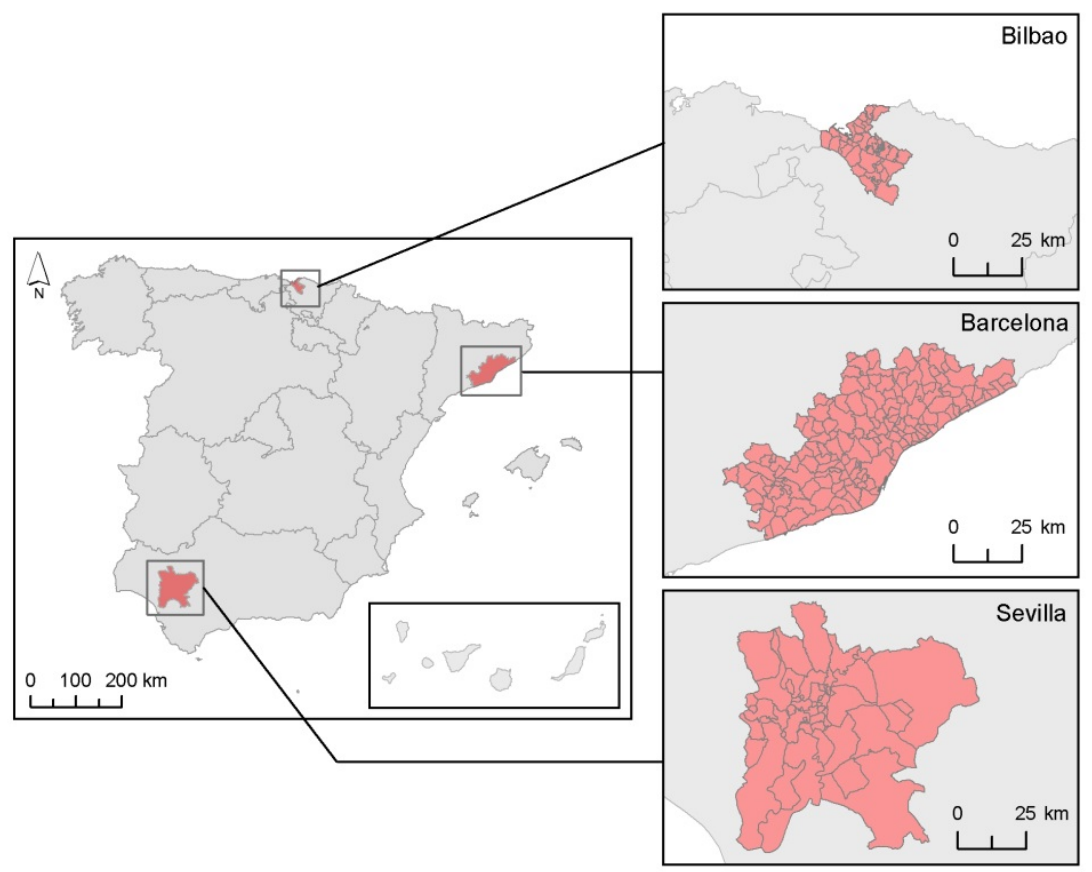

Fuente: elaboración propiaa partir de los planes analizados.

Como puede desprenderse de la Tabla 3 y de la Figura 1, a pesar de pertenecer al rango superior de la jerarquía metropolitana española, hay unas significativas diferencias dimensionales entre los tres ámbitos, que en gran parte van a explicar el diferente alcance, orientación y contenido de los planes de ordenación territorial que les afectan. El de Barcelona (Figura 2) corresponde a una región metropolitana con casi cinco millones de habitantes, pero sobre todo de una gran complejidad funcional y estructural, tanto en lo que se refiere al medio geográfico como en lo concerniente al despliegue del sistema de poblamiento, infraestructuras y actividades productivas. Ello justifica una orientación fundamentalmente estratégica del Plan, por encima de determinaciones y propuestas de diseño físico concreto de las intervenciones.

En el otro extremo, el Plan del área metropolitana de Bilbao (Figura 3) abarca un ámbito más reducido que el que podría delimitarse a partir de criterios funcionales (como los habituales basados en la movilidad residencia-trabajo), con una población que no alcanza el millón de habitantes pero que se concentra en unos $500 \mathrm{kms}^{2}$, prácticamente el área conurbada en torno a la ciudad central. En este caso, consecuentemente, el Plan tiene un contenido y una organización más parecidos a un plan urbanístico convencional, con un alcance y precisión de las determinaciones y las propuestas de intervención mucho más detallada tanto en términos cartográficos como programáticos. 
Figura 2

PLAN TERRITORIAL METROPOLITANO DE BARCELONA: SISTEMA DE ESPACIOS ABIERTOS

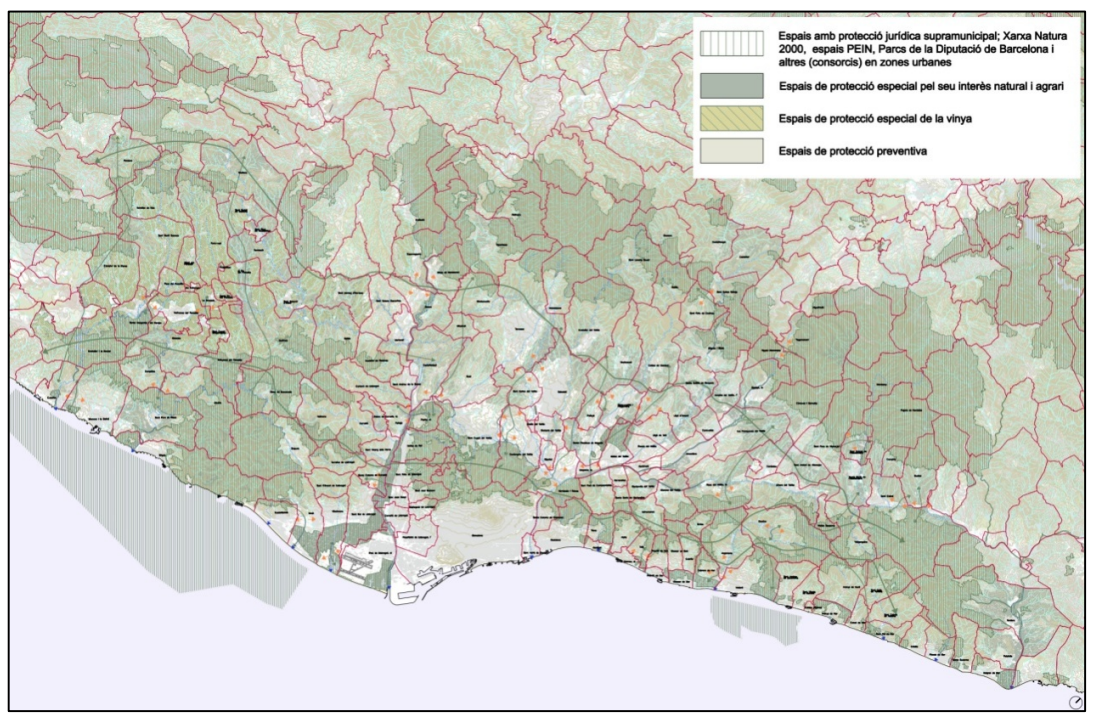

Fuente: Plan Territorial Metropolitano de Barcelona (2010).

Figura 3

PLAN TERRITORIAL PARCIAL DE BILBAO METROPOLITANO: MALLA VERDE

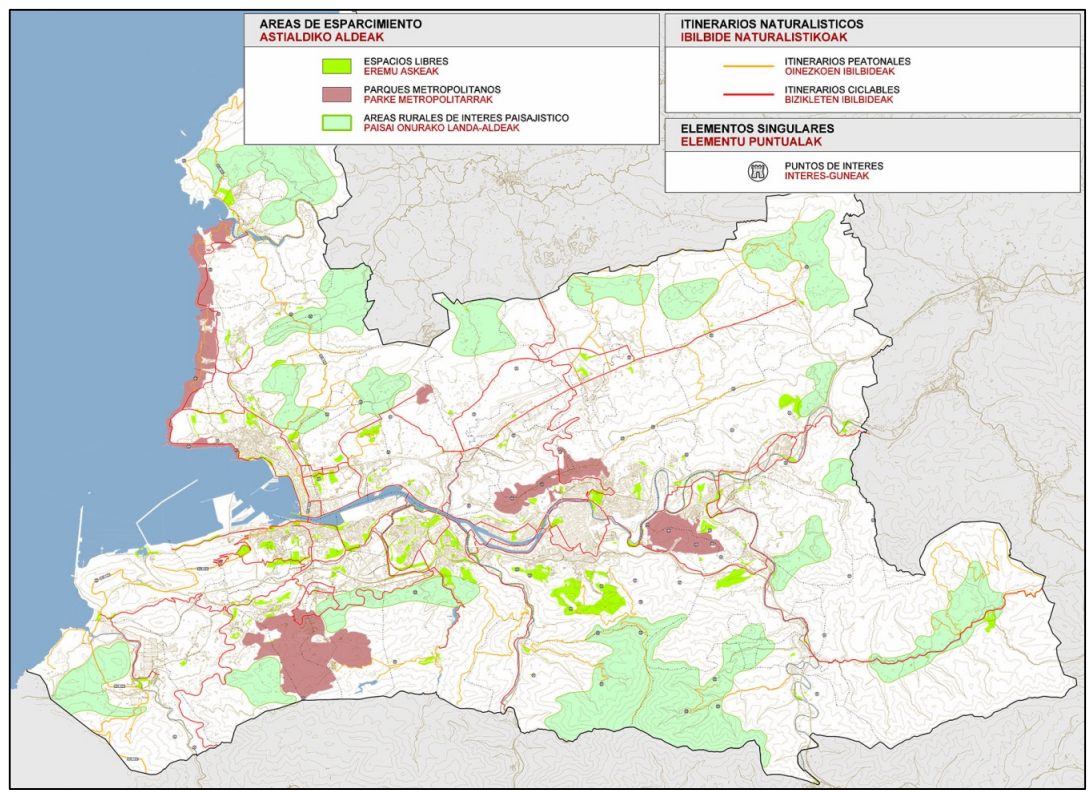

Fuente: Plan Territorial Parcial de Bilbao Metropolitano (2006). 
Entre ambos extremos, el caso del Plan metropolitano de Sevilla (Figura 4) presenta sobre todo la singularidad de abarcar un territorio muy amplio, debido fundamentalmente a la extensión superficial de algunos de los términos municipales de la corona metropolitana. Ello supone que se aborde un espacio con una densidad o proporción de suelos artificiales mucho menor, lo que por otra parte supone alícuotamente una presencia de elementos y recursos potenciales para la infraestructura verde muy significativa. De cualquier forma, al igual que en el ejemplo de Barcelona, el Plan opta por una orientación estratégica y directiva que no desciende en la mayoría de las ocasiones a propuestas concretas y detalladas.

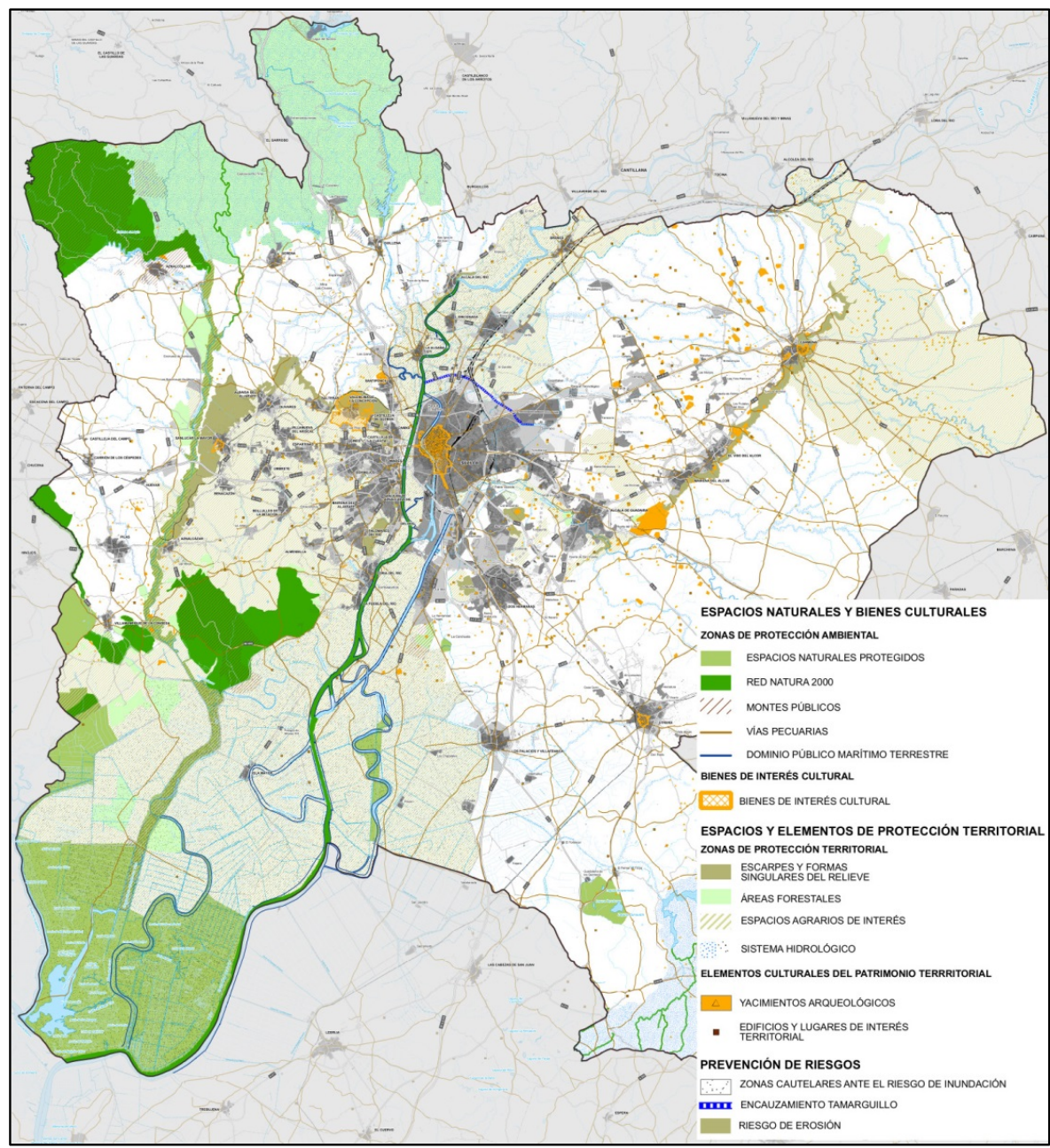

Fuente: Plan de Ordenación del Territorio de la Aglomeración Urbana de Sevilla (2009). 
Dado que, como se ha indicado, ninguno de los planes utiliza explícitamente el término infraestructura verde, el análisis se focaliza sobre los contenidos relativos a la ordenación del espacio libre metropolitano, entendido éste en un sentido amplio como el conjunto del territorio no construido o dedicado a usos estrictamente urbanos. En el caso de Barcelona, esta cuestión se aborda a través del concepto de Sistema de Espacios Abiertos; en el de Bilbao, mediante el concepto de Malla Verde; y en el de Sevilla, por medio del concepto genérico de espacio libre, que incluye tanto la Red de Espacios de Uso Público como el denominado Sistema de Protección Territorial. En cada uno de los planes se analizará, primero, el reconocimiento o no de los elementos y recursos territoriales señalados anteriormente como potenciales componentes de la infraestructura verde metropolitana. A partir de ello se evaluará, en segundo lugar, la funcionalidad asignada a dichos componentes, comprobando si tal reconocimiento es meramente enunciativo o se materializa en determinaciones concretas bien de carácter normativo, bien en actuaciones de intervención específicas.

Tabla 4

COMPONENTES DE LA INFRAESTRUCTURA VERDE METROPOLITANA EN LOS PLANES ANALIZADOS

\begin{tabular}{|c|c|c|c|}
\hline \multirow[b]{2}{*}{ Componentes } & \multicolumn{3}{|c|}{ Plan } \\
\hline & Barcelona & Bilbao & Sevilla \\
\hline \multicolumn{4}{|l|}{ Espacios libres y otros elementos ligados al tejido urbano } \\
\hline Parques periurbanos y metropolitanos & SI & SI & SI \\
\hline Parques urbanos & SI & SI & NO \\
\hline Otros espacios abiertos urbanos con vegetación & SI & SI & SI \\
\hline Elementos arquitectónicos (fachadas y cubiertas vegetales) & NO & NO & NO \\
\hline \multicolumn{4}{|l|}{ Espacios naturales / forestales } \\
\hline Áreas naturales protegidas & SI & SI & SI \\
\hline Zonas naturales / forestales sin protección & SI & SI & SI \\
\hline Zonas multifuncionales con valor ambiental & SI & SI & SI \\
\hline \multicolumn{4}{|l|}{ Espacios agrarios } \\
\hline Huertos urbanos / periurbanos & NO & NO & NO \\
\hline Parques agrícolas o similares & SI & NO & $\mathrm{NO}$ \\
\hline Usos agrícolas (con carácter extensivo) & SI & SI & SI \\
\hline \multicolumn{4}{|l|}{ Elementos lineales y de conexión } \\
\hline Elementos lineales de conexión ecológica & SI & NO & SI \\
\hline Elementos lineales de conexión para uso público & NO & SI & SI \\
\hline Red fluvial (dominio público) (puede ser redundante) & SI & SI & SI \\
\hline Vías pecuarias (dominio público) (puede ser redundante) & NO & SI & SI \\
\hline \multicolumn{4}{|l|}{ Elementos puntuales } \\
\hline Elementos del patrimonio cultural (yacimientos, haciendas...) & NO & SI & SI \\
\hline Otros elementos puntuales (miradores, áreas de descanso...) & $\mathrm{NO}$ & SI & $\mathrm{NO}$ \\
\hline Otros elementos & $\begin{array}{c}\text { Patrimonio } \\
\text { geológico }\end{array}$ & $\begin{array}{c}\text { Elementos } \\
\text { costeros }\end{array}$ & NO \\
\hline
\end{tabular}

Fuente: elaboración propia a partir de los planes analizados. 
En lo que se refiere a los componentes de la infraestructura verde, la Tabla 4 muestra los elementos tomados en consideración por los diferentes planes. En el bloque de los elementos extensivos del territorio, el subconjunto que aparece en todos los planes y en sus diferentes modalidades es el de los espacios naturales/forestales. Se trata ésta de la categoría tradicionalmente asociada a la protección del territorio frente al proceso urbanizador en planes urbanísticos y territoriales, tanto porque sea obligatorio - es el caso de las áreas protegidas-, como porque tengan valores ambientales reseñables o por su capacidad de contención del crecimiento urbano. En los casos de Barcelona, con el patrimonio geológico, y de Bilbao, con las áreas costeras y de marisma, se añaden unas categorías singulares que dotan de mayor variedad y complejidad al tratamiento de este bloque.

Por su parte, los espacios libres y otros elementos ligados al tejido urbano también tienen una casi unánime presencia en los planes, aunque por distintas razones, ya que se trata de componentes definidos por su naturaleza más activa y no meramente "defensiva". De hecho, los únicos que no aparecen reflejados en los planes son aquellos que por su escala no son considerados relevantes para una ordenación metropolitana, como es el caso de las fachadas y cubiertas vegetales. Sí resulta reseñable, de otro lado, la no consideración de los parques urbanos en el Plan metropolitano de Sevilla, probablemente por una cuestión de competencia administrativa. Por último, el apartado de espacios agrarios aparece reflejado todavía de una manera indecisa, sólo recogida en algunos casos por sus valores patrimoniales o de defensa territorial (los parques agrarios del plan de Barcelona) o bien por su valores paisajísticos (en el Plan de Sevilla), pero nunca en su condición "per se" de espacio libre del territorio metropolitano.

En referencia al bloque de elementos lineales, el Plan metropolitano de Sevilla es el más exhaustivo a la hora de recoger los diferentes componentes, tanto en lo que se refiere a los corredores fluviales como a caminos rurales y otros elementos lineales de origen antrópico, bien sea por su función de uso público o como conector ecológico. El Plan de Bilbao se centra en los caminos y vías rurales en función de su uso público, en una perspectiva claramente de plan urbanístico y sin prestar atención a los corredores fluviales. Por el contrario, el Plan de Barcelona, dentro de una perspectiva metodológica de ecología del paisaje, se centra en esos ejes fluviales como conectores ecológicos, dejando a un lado los caminos y vías rurales así como todo lo asociado a su uso público. Finalmente, por su propia naturaleza y escala, los componentes puntuales tienen una muy reducida presencia en los tres planes, siendo prácticamente inexistentes en el de Barcelona, y estando limitados en los casos de Bilbao y Sevilla a determinados elementos patrimoniales de carácter arqueológico y arquitectónico. Sí debe mencionarse que en el caso de Bilbao se identifican una serie de nodos (miradores, áreas de descanso, etc.) asociados a la red de caminos rurales de uso público, que indirectamente reflejan la condición de funcionamiento en red de este sistema infraestructural.

Mientras que, como se ha visto, hay una presencia bastante mayoritaria de los componentes asociados a la infraestructura verde, en lo que se refiere a sus funciones el reconocimiento y tratamiento de las mismas es mucho más limitado. Si se observa la Tabla 5, se puede comprobar que en solo tres dimensiones funcionales hay una completa unanimidad en un tratamiento completo y comprehensivo en los planes analizados. Son la "protección de suelos inundables", la "conservación de suelos productivos", y la "regulación del crecimiento urbano y la conurbación”, tres cuestiones tradicionalmente presentes en los planes urbanísticos y territoriales y claramente vinculadas a una perspectiva meramente pasiva o defensiva, frente al crecimiento urbano, de las potenciales funciones de estos componentes. 


\begin{tabular}{|c|c|c|c|}
\hline \multirow[b]{2}{*}{ Funciones } & \multicolumn{3}{|c|}{ Plan } \\
\hline & Barcelona & Bilbao & Sevilla \\
\hline \multicolumn{4}{|l|}{ Funciones recreativas y de ocio } \\
\hline Espacio para actividades recreativas y deportivas & $\mathrm{NO}$ & SI & PARCIAL \\
\hline Contacto con la naturaleza & NO & SI & PARCIAL \\
\hline Otras actividades de uso público (culturales, educativas...) & NO & PARCIAL & PARCIAL \\
\hline \multicolumn{4}{|l|}{ Funciones relacionadas con la biodiversidad } \\
\hline Conservación de hábitats naturales & PARCIAL & SI & PARCIAL \\
\hline Desplazamiento de especies (conectividad, permeabilidad) & SI & NO & NO \\
\hline \multicolumn{4}{|l|}{ Funciones relacionadas con la calidad ambiental y la salud } \\
\hline $\begin{array}{l}\text { Mitigación del cambio climático (captación y retención } \\
\text { de } \mathrm{CO}_{2} \text { ) }\end{array}$ & NO & NO & NO \\
\hline Mejora de la calidad del aire / absorción de contaminantes & NO & NO & $\mathrm{NO}$ \\
\hline Regulación de la temperatura urbana / isla de calor & NO & NO & NO \\
\hline \multicolumn{4}{|l|}{ Funciones hidrológicas } \\
\hline Protección de zonas inundables & SI & SI & SI \\
\hline Drenaje y prevención de la escorrentía superficial & $\mathrm{NO}$ & SI & NO \\
\hline Depuración del agua & $\mathrm{NO}$ & $\mathrm{NO}$ & NO \\
\hline \multicolumn{4}{|l|}{ Funciones relacionadas con el espacio agrícola } \\
\hline Producción de alimentos y seguridad alimentaria & NO & NO & NO \\
\hline Conservación del suelo productivo & SI & SI & SI \\
\hline \multicolumn{4}{|l|}{ Funciones territoriales / urbanisticas } \\
\hline Regulación del crecimiento urbano y la conurbación & SI & SI & SI \\
\hline Fomento de la movilidad no motorizada & NO & SI & PARCIAL \\
\hline \multicolumn{4}{|l|}{ Funciones relacionadas con el patrimonio cultural } \\
\hline Conservación del patrimonio histórico / cultural & PARCIAL & PARCIAL & PARCIAL \\
\hline Preservación del paisaje & SI & PARCIAL & PARCIAL \\
\hline
\end{tabular}

Sí: se considera está función de forma explícita y se establecen determinaciones para preservarla o potenciarla; Parcial: se menciona esta función, pero no se profundiza en ella ni se establecen medidas específicas; No: no se contempla esta función.

Fuente: elaboración propia a partir de los planes analizados.

Cuando se trata de funciones que requieren una aproximación más activa, los planes en general se retraen y son mucho más modestos en sus propuestas. Debe destacarse el esfuerzo del Plan de Bilbao en lo que se refiere al uso público, con propuestas detalladas y concretas de intervención, y el Plan de Barcelona en lo que se refiere a políticas activas en relación con la conservación, mejora y promoción de los recursos paisajísticos del ámbito. Por su parte, el Plan de Sevilla, aunque realiza un esfuerzo notable en reconocer un amplio conjunto de funciones, posteriormente no materializa tal esfuerzo ni en contenidos normativos ni en 
actuaciones de intervención concretas en materias por ejemplo de uso público o conservación del patrimonio cultural y el paisaje. Por último, resulta significativo constatar en los tres planes la ausencia de referencias a determinados servicios ecológicos potenciales de la infraestructura verde como pueden ser los relativos a la calidad ambiental y la salud, la producción y la seguridad alimentaria o la depuración de aguas, lo cual en definitiva está señalando un todavía muy limitado y pobre entendimiento de las capacidades funcionales que se atribuyen a esta infraestructura.

\section{DISCUSIÓN: AFINIDAD DE LOS PLANES METROPOLITANOS AL CONCEPTO DE INFRAES- TRUCTURA VERDE}

El análisis desarrollado en el apartado anterior permite afirmar que los tres documentos estudiados representan, aún de forma parcial y con diferencias importantes entre ellos, una primera aproximación a la articulación de infraestructuras verdes de escala metropolitana, al menos en lo que respecta a los componentes y funciones asociados a estas estructuras. El siguiente paso es evaluar en qué medida la ordenación de los componentes y funciones considerados por cada Plan se traducen en una propuesta sólida y de carácter sistémico, capaz de responder a los tres rasgos esenciales identificados para la infraestructura verde: la conectividad, la multifuncionalidad y el enfoque pro-activo de ordenación.

\section{V.1. Conectividad}

De los tres rasgos citados, la conectividad es el que aparece reflejado de forma más explícita en los documentos analizados. Sin embargo, y aunque los tres planes adoptan la idea de conectividad como principio o criterio básico de intervención en sus propuestas relativas al espacio libre, cada uno de los planes lo hace desde una perspectiva diferente. En el caso de Barcelona, el plan entiende la conectividad como una garantía para la preservación de los procesos y flujos ecológicos presentes en el territorio metropolitano. Como se ha indicado, esta aproximación al concepto está claramente ligada a los principios teóricos y metodológicos de la ecología del paisaje, que constituyen de hecho el fundamento de los análisis del medio natural realizados con carácter previo a la redacción del Plan. Por ello, en el plano propositivo y normativo, el Plan apuesta por trazar una serie de conectores a modo de líneas de flujo en determinados sectores clave del espacio metropolitano, entendiendo el sistema de espacios abiertos más como un continuo territorial que como una red de espacios discretos. En contraste, el Plan de Bilbao ofrece una propuesta de conexión centrada exclusivamente en el uso público, y materializada a través de un conjunto de itinerarios blandos que unen los diferentes espacios libres incluidos en la malla verde. La propuesta resultante dibuja una estructura bien definida y articulada espacialmente, aunque limitada desde el punto de vista de la funcionalidad ecológica. Por último, en el caso de Sevilla la aproximación al concepto de conectividad representa un término medio entre los dos anteriores. Las propuestas de conexión entre los espacios libres metropolitanos y los centros urbanos se articulan en este Plan alrededor de dos tipos de red: la de corredores verdes y la de ejes fluviales de uso público. En ambos casos se tienen en consideración aspectos ambientales, pero el planteamiento se orienta en mayor medida al uso público; de 
hecho, el propio Plan llega a reconocer las limitaciones de los corredores lineales para una conservación satisfactoria de los flujos de carácter natural o ecológico, y aboga para este fin por entender el espacio libre como una matriz territorial continua. Sin embargo, esta segunda perspectiva no se materializa en propuestas concretas para preservar la continuidad y permeabilidad ecológica del territorio.

En suma, se observan importantes divergencias en cuanto a la interpretación que se hace del concepto de conectividad, que es utilizado para abordar aspectos funcionales diferentes: la conservación de los flujos ecológicos, el fomento de la movilidad sostenible vinculada al uso público y la preservación de la continuidad del territorio no urbanizado frente al crecimiento urbano. Por otro, las propuestas desarrolladas para mejorar la conectividad difieren también significativamente en cuanto a su alcance y grado de concreción.

\section{V.2. Multifuncionalidad}

Aunque en ninguno de los documentos analizados se hace una mención explícita a la idea de multifuncionalidad, como se ha comprobado en el apartado anterior, los tres planes analizados asignan a los componentes de la infraestructura verde un rango relativamente amplio y diverso de funciones y beneficios de diversa naturaleza. No obstante, tanto el conjunto específico de funciones consideradas por cada plan como la orientación y el nivel de detalle con que se abordan presentan diferencias notables. Así, en el caso de Barcelona, el enfoque funcional tiene un claro sesgo ambiental, primándose los aspectos ecológicos y paisajísticos. El Plan de Bilbao presenta por su parte un carácter más orientado al uso público, complementándose esta función con la protección de espacios rurales con valores paisajísticos y naturales destacados. Finalmente, el Plan de Sevilla resulta quizá el más avanzado en el aspecto conceptual, con mención de un numeroso conjunto de funciones de carácter social, cultural, ambiental, paisajístico, productivo y relativo a la prevención de riesgos, si bien no alcanza este mismo nivel de desarrollo en su apartado propositivo.

En una visión transversal, la referencia compartida en los tres planes analizados a la prevención de riesgos naturales -sobre todo en relación a los suelos inundables-, a la conservación del suelo productivo frente a los cambios de uso, y a la regulación de los procesos de conurbación y crecimiento urbano difuso, es un reflejo de la preocupación de la ordenación territorial por dotar de límites razonables al crecimiento de la ciudad. Los planes coinciden así con una de las finalidades básicas asociadas a la infraestructura verde en ámbitos urbanizados: la de prevenir el fenómeno de urban sprawl y favorecer un dimensionamiento y una configuración espacial más equilibradas para los procesos de expansión urbana. En contraste con ello, y como se ha mencionado, la ausencia de otras funciones o servicios ambientales más específicos, más allá de alguna mención de carácter puntual, es quizá el aspecto más deficiente en relación a la dimensión funcional de la infraestructura verde. Es posible entender que estos servicios se encuentran recogidos de forma implícita en las propuestas relativas a la conservación de las masas forestales y el arbolado urbano, agrupándose bajo el objetivo genérico de la mejora de la calidad ambiental. No obstante, cabría esperar una mayor atención a los mismos en el apartado propositivo con medidas concretas para su potenciación, al tratarse de funciones que permiten abordar algunos de los principales desequilibrios ambientales de los actuales sistemas urbanos. 


\section{V.3. Enfoque pro-activo}

La dificultad de los planes para adoptar un enfoque pro-activo en la ordenación del espacio no construido es probablemente el aspecto que más los distancia de la noción de infraestructura verde. En el caso de Barcelona, por ejemplo, la propia definición de espacio libre es planteada de forma subsidiaria como el conjunto del suelo no urbanizable según lo establecido en los planes urbanísticos vigentes. En consonancia, el enfoque de ordenación tiene un carácter fundamentalmente preventivo, orientándose en esencia al control del desarrollo urbanístico y la implantación de edificaciones en los espacios abiertos. El Plan no contempla en su apartado económico ni objetivos ni líneas de actuación específicas en esta materia, ni tampoco asigna competencias o define plazos para posibles intervenciones. Por su parte, la agenda del Plan prevé la elaboración de Planes Territoriales Sectoriales para el espacio agrario metropolitano y los conectores ecológicos, pero no detalla contenidos ni plazos específicos de desarrollo para estos instrumentos.

En el caso de Sevilla, los fundamentos en los que se basa la propuesta de ordenación son ambiciosos, pero no logran materializarse -más allá de los planteamientos preventivos y reguladores- en un verdadero enfoque estratégico de intervención. El Plan establece la protección cautelar de los suelos asociados a la denominada Red de Espacios Libres, define directrices de intervención en estos ámbitos, y recomienda ( de un ente de gestión supramunicipal para coordinar la actuación pública en esta materia; sin embargo, el desarrollo específico de las propuestas se delega en gran medida en los planes urbanísticos municipales y en instrumentos sectoriales de intervención.

Por último, el Plan de Bilbao es quizá el que presente una propuesta de ordenación más concreta, estructurada y de carácter sistémico, que trasciende en mayor medida la mera regulación de usos o la recapitulación de figuras y regímenes de protección preexistentes. En consecuencia, el Plan presenta una previsión de gasto en esta materia, define los plazos de intervención y ofrece, a través del apartado de acciones estructurantes y operaciones estratégicas, un desarrollo detallado para algunas de las propuestas (p. ej. la red de itinerarios de la malla verde). Es evidente, como se ha apuntado anteriormente, que la menor escala de este Plan constituye un factor determinante para entender el grado de detalle alcanzado en sus contenidos propositivos.

\section{CONCLUSIONES}

La noción de infraestructura verde parece estar consolidándose como un concepto clave en el ámbito de la planificación territorial, tanto por su valor intrínseco como "conceptopuente" capaz de facilitarla comunicación interdisciplinar, como por la rapidez con que está siendo adoptado por parte de numerosos actores institucionales y técnicos en el plano internacional. Su interés no reside tanto en el carácter novedoso de sus planteamientos teóricos -que, como se ha visto, se encuentran ya plena o parcialmente recogidos en instrumentos de ordenación que no recurren de forma explícita a este concepto-, sino en su capacidad para aunar un conjunto de criterios de intervención muy específicos en un marco conceptual flexible y sencillo de aplicar, que resulta particularmente adecuado para su incorporación a las 
políticas y estrategias de desarrollo urbano y territorial sostenible. No obstante, más allá de su exitosa difusión, o quizá precisamente como consecuencia de su rápida acogida y aplicación en contextos muy diversos, se han detectado ciertas carencias o debilidades en relación a su concepción teórica. En las páginas anteriores se ha podido constatar que la falta de consenso acerca de una definición unitaria para la infraestructura verde da pie a un cierto grado de dispersión e incluso confusión en el empleo del término, sobre todo en un plano aplicado, observándose importantes divergencias tanto en lo que respecta a su finalidad como a su escala de aplicación. Para el caso específico de las infraestructuras verdes metropolitanas, este trabajo ha tratado de avanzar en la concreción de sus principales requisitos y rasgos estructurales y funcionales, y ha permitido comprobar cómo, al menos para el contexto español, una parte significativa de dichos rasgos están ya siendo asumidos por los principales planes metropolitanos en lo que respecta a la ordenación del espacio libre.

En este sentido, desde el punto de vista estructural, los planes analizados incorporan en sus propuestas un número significativo de espacios y elementos vinculados a la noción de infraestructura verde y adoptan la conectividad como principio fundamental. También, desde el punto de vista funcional, se encuentran -como mínimo a nivel de discurso- en sintonía con el concepto de multifuncionalidad exigido a estos sistemas. El aspecto en el que los planes divergen en mayor medida de los presupuestos teóricos de la infraestructura verde es en lo que respecta al carácter proactivo y estratégico de la ordenación. Los tres casos de estudio realizan un esfuerzo de catalogación de los principales recursos y valores naturales a conservar frente a la urbanización y establecen medidas de carácter preventivo para garantizar su protección, pero no logran desprenderse en su desarrollo normativo de ciertas inercias ligadas a la tradición urbanística, como serían el carácter subsidiario otorgado al espacio libre frente a la ordenación del crecimiento urbano y la visión excesivamente conservacionista -y no orientada a una puesta en valor de los recursos- sobre el patrimonio natural y paisajístico. El análisis comparado muestra además algunas limitaciones que parecen intrínsecas de la escala de planificación considerada, y que se refieren tanto al grado de desarrollo y concreción alcanzado en las propuestas, como a las garantías para su adecuada ejecución y gestión. A este respecto, queda patente que la ordenación en detalle de los componentes que integran la infraestructura verde escapa del alcance de un instrumento de planificación de naturaleza metropolitana, y que la amplitud y la complejidad administrativa del ámbito de ordenación inciden de forma muy significativa en el mayor o menor nivel de concreción alcanzado en sus apartados propositivo y normativo. En todo caso, cabría esperar que los planes evitaran una excesiva delegación en otros instrumentos subsidiarios -ya sean de carácter sectorial o de ordenación municipal- e hicieran un esfuerzo propositivo e instrumental para dotar de contenido concreto a sus planteamientos, que ayude a garantizar la cohesión y el funcionamiento integrado del sistema verde.

En ese sentido, se pueden señalar dos vías, ambas apuntadas de forma más o menos explícita en los documentos analizados, por las que sería posible mejorar la efectividad de las determinaciones relativas al espacio libre y avanzar más allá de un enfoque excesivamente centrado en la preservación de los valores territoriales existentes. La primera de ellas supone aprovechar la capacidad de los planes metropolitanos para construir, en un sentido positivo, la infraestructura verde, no sólo protegiendo o recuperando los recursos locales preexistentes, sino generando nuevos elementos cuando sea necesario para responder a demandas 
funcionales concretas o para mejorar el funcionamiento en conjunto del sistema. Un ejemplo de ello lo constituyen algunas de las propuestas analizadas en materia de la generación de itinerarios para la movilidad sostenible. La segunda de las vías citadas está relacionada con la previsión de mecanismos de gestión y monitorización. En esta línea, parece fundamental establecer de forma concluyente un marco adecuado para la materialización de las propuestas relativas a la infraestructura verde, que contemple la asignación de competencias específicas, la creación -si fuera necesario- de un órgano de coordinación supramunicipal y abierto a la participación de los diferentes actores implicados, la definición detallada de plazos y partidas presupuestarias, y la aportación de una cartografía de ordenación con el suficiente nivel de detalle para orientar el contenido de los instrumentos derivados o subsidiarios.

Más allá de estas consideraciones, los planes estudiados representan -al menos para el contexto español- un claro avance frente a las anteriores experiencias de intervención sobre la cuestión, que al haberse vinculado fundamentalmente al planeamiento urbanístico municipal, presentaban una evidente limitación, sobre todo en cuanto a la escala de actuación. El conjunto de los elementos naturales y espacios no construidos comienza a entenderse a través de estos instrumentos de escala metropolitana como una estructura cohesionada, a la vez en su configuración física y en su dimensión funcional, emergiendo como un componente activo y valioso del sistema territorial. Si bien este hecho no es suficiente para considerar las propuestas analizadas como una materialización completa del concepto de infraestructura verde, sí se pueden entender como un punto de partida -y en determinados aspectos, un referente para futuras actuaciones- para una implementación efectiva y coherente del mismo. En conclusión, se puede afirmar que la planificación metropolitana posee ya recursos conceptuales e instrumentales para avanzar hacia un mayor equilibrio entre las dimensiones artificial y natural de los grandes sistemas urbanos.

\section{BIBLIOGRAFÍA}

AGENCIA EUROPEA DE MEDIO AMBIENTE (AEMA) (2011): Green infrastructure and territorial cohesion. The concept of green infrastructure and its integration into policies using monitoring systems. Luxemburgo: Publications Office of the European Union. Disponible en:

http://www.eea.europa.eu/publications/green-infrastructure-and-territorial-cohesion

AGENCIA EUROPEA DE MEDIO AMBIENTE (AEMA) (2015): Exploring nature-based solutions. The role of green infrastructure in mitigating the impacts of weather-and climate change-related natural hazards. Luxemburgo: Publications Office of the European Union.Disponible en:

http://www.eea.europa.eu/publications/exploring-nature-based-solutions-2014

AHERN, J. (1995): “Greenways as a planning strategy". Landscape and Urban Planning, $\mathrm{n}^{\circ}$ $33,131-155$.

BENEDICT, M. y MCMAHON. E. (2002): Green Infrastructure: Smart Conservation for the 21st Century.Washington D.C.: Sprawl Watch Clearinghouse. Disponible en: http://www.sprawlwatch.org/greeninfrastructure.pdf

BETTINI, V. (Ed.) (1998): Elementos de ecología urbana. Madrid: Ed. Trotta. 
BOLUND, P. y HUNHAMMAR, S. (1999): "Ecosystem services in urban areas". Ecological Economics, $\mathrm{n}^{\circ} 29,293-301$.

CHIESURA, A. (2004): "The role of urban parks for the sustainable city". Landscape and Urban Planning, vol. 68, p. 129-138.

COMISIÓN EUROPEA (2013): Green Infrastructure (GI) - Enhancing Europe's Natural Capital. Communication from the Commission to the European Parliament, the Council, the European Economic and Social Committee and the Committee of the Regions. [COM (2013) 249 final]. Bruselas: Comisión Europea,.Disponible en: http://eur-lex.europa.eu/legal-content/EN/TXT/?uri=celex\%3A52013DC0249

FERIA, J. M. (2004): "Problemas de definición de las áreas metropolitanas en España". Boletín de la Asociación de Geógrafos Españoles, $\mathrm{n}^{\circ}$ 38, 85-100.

FERIA, J. M (Ed.) (2012): Territorial Heritage and Development. London: Taylor \& Francis. FERIA, J. M., RUBIO, M. y SANTIAGO, J. (2005): "Los Planes de ordenación del territorio como instrumentos de cooperación”. Boletín de la Asociación de Geógrafos Españoles, $\mathrm{n}^{\mathrm{o}} 39,87-116$.

FERIA, J. M. y SANTIAGO, J. (2009): "Funciones ecológicas del espacio libre y planificación territorial en ámbitos metropolitanos: perspectivas teóricas y experiencias recientes en el contexto español". Scripta Nova, 13, nº 299.

FERIA, J.M. y SANTIAGO, J. (2016): "El concepto de infraestructura verde y su potencial aplicación a los instrumentos de ordenación territorial de escala metropolitana". En Queirós, M., Louro, A., Maciel, P. (Coords.): O desafio do planeamento e observação territorial nos países Ibero-americanos para o século XXI: dinâmicas, processos, experiências e propostas. p. 107-118. Lisboa: RIDOT, Instituto de Geografia e Ordenamento do Território / Universidade de Lisboa.

GENERALITAT VALENCIANA (2013): Plan de Infraestructura Verde y Paisaje de la Comunitat Valenciana. Valencia: Generalitat Valenciana. Disponible en: http://www.upv.es/contenidos/CAMUNISO/info/778623normalc.html

ELMQVIST, T. et al.(2013): Urbanization, Biodiversity and Ecosystem Services: Challenges and Opportunities. A Global Assessment. Berlín: Springer.

FARRUGIA, S., HUDSON, M.D. y MCCULLOCH, L. (2013): “An evaluation of flood control and urban cooling ecosystem services delivered by urban green infrastructure". International Journal of Biodiversity Science, Ecosystem Services \& Management, $\mathrm{n}^{\circ} 9$, 136-145.

FOLCH, R. (Ed.) (2003): El territorio como sistema. Barcelona: Diputación de Barcelona.

FORMAN, R. T. T. y GODRON, M. (1986): Landscape Ecology. Nueva York: John Wiley $\&$ Sons.

FORMAN, R. T. T. (2008): Urban Regions. Ecology and Planning Beyond the City. Nueva York: Cambridge University Press.

FUSARO, L. et al. (2015): "Urban and peri-urban forests in the metropolitan area of Rome: Ecophysiological response of Quercus ilex L. in two green infrastructures in an ecosystem services perspective". Urban Forestry and Urban Greening, ${ }^{\circ}$ 14, 1147-1156.

GEDDES, P. (1915): Cities in Evolution. An Introduction to the Town Planning Movement and to the Study of Civics. Londres: Williams and Norgate. 
HALL, P. (1998): Cities in Civilization: Culture, Technology, and Urban Order. New York: Pantheon Books.

HECKERT, M. y ROSAN, C.D. (2016): “Developing a green infrastructure equity index to promote equity planning". Urban Forestry and Urban Greening.

HOUGH, M. (1998): Naturaleza y ciudad. Planificación urbana y procesos ecológicos. Barcelona: Editorial Gustavo Gili.

JIA, Z., TANG, S., LUO, W., LI, S. y ZHOU, M. (2016): "Small scale green infrastructure design to meet different urban hydrological criteria". Journal of Environmental Management, $\mathrm{n}^{\mathrm{o}} 171,92-100$.

JONGMAN, R., KÜLVIK, M. y KRISTIANSEN, I. (2004): “European ecological networks and greenways". Landscape and urban planning, $\mathrm{n}^{\circ}$ 68, 305-319.

KIM, G., MILLER, P.A. y NOWAK, D.J. (2015): “Assessing urban vacant land ecosystem services: Urban vacant land as green infrastructure in the City of Roanoke, Virginia". Urban Forestry and Urban Greening, $\mathrm{n}^{\circ}$ 14, 519-526.

LANDSCAPE INSTITUTE (2009): Green infrastructure: connected and multifunctional landscapes - position document. London: Landscape Institute. Disponible en: http://www.landscapeinstitute.org/PDF/Contribute/GreenInfrastructurepositionstatement13May09.pdf

LEWELLYN, C., LYONS, C.E., TRAVER, R.G. y WADZUK, B.M. (2016): “Evaluation of seasonal and large storm runoff volume capture of an infiltration green infrastructure system". Journal of Hydrologic Engineering, vol. 21, $\mathrm{n}^{\circ} 1$.

MAGONI, M. y COLUCCI, A. (2015): "Protection of Peri-Urban Open Spaces and FoodSystem Strategies. The Case of Parco delle Risaie in Milan". Planning Practice and Research.

MANDER, Ü., WIGGERING, H. y HELMING, K. (Eds.) (2007): Multifunctional land use. Meeting future demands for landscape goods and services. Berlín: Springer.

MANES, F. et al. (2014): "Urban ecosystem services: Tree diversity and stability of $\mathrm{PM}_{10}$ removal in the metropolitan area of Rome". Annali di Botanica, $\mathrm{n}^{\circ} 4$, 19-26.

McHARG, I. (1969): Design with Nature. Nueva York: Natural History Press.

MOMM-SCHULT, S.I., PIPER, J., DENALDI, R., FREITAS, S.R., FONSECA, M.L.P. y OLIVEIRA, V.E. (2013): "Integration of urban and environmental policies in the metropolitan area of Sao Paulo and in Greater London: the value of establishing and protecting green open spaces". International Journal of Urban Sustainable Development, $\mathrm{n}^{\circ} 5$, 89-104.

MUMFORD, L. (1956): “The natural history of urbanization”. En: WILLIAM L. THOMAS, jr (Ed.), Man's Role in the Changing the Face of the Earth. Chicago \& London: Univ. of Chicago Press.

MYLES, K. (2015): Economic benefits of low impact development and green infrastructure: Case studies. Nueva York: Nova Science Publishers.

NATURAL ENGLAND (2010): Natural England - Green Infrastructure. York: Natural England.

OECD (2001): Multifunctionality: Towards an analytical framework. París: OECD. Disponible en: http://www.oecd.org/tad/agricultural-policies/40782727.pdf 
OECD (2012): Redefining “Urban”. A new Way to Measure Metropolitan Areas. París: OECD. Disponible en: http://www.oecd.org/regional/redefiningurbananewwaytomeasuremetropolitanareas.htm

OPDAM, P., STEINGRÖVER, E. y VAN ROOIJ, S. (2005): "Ecological networks: a spatial concept for multi-actor planning of sustainable landscapes". Landscape and Urban Planning, $\mathrm{n}^{\mathrm{o}} 75,322-332$.

SANTIAGO, J. (2008): La naturaleza en la ciudad: perspectivas teóricas y metodológicas para el estudio de la funcionalidad ambiental del espacio libre. Sevilla: Consejería de Obras Públicas y Transportes.

SORIA, A. (1997): "En pro de una red peninsular de parques lineales". Ciudad y Territorio, $\mathrm{n}^{\mathrm{o}} 111,31-47$.

TZOULAS et al. (2007): "Promoting ecosystem and human health in urban areas using green infrastructure: a literature review". Landscape and Urban Planning, $\mathrm{n}^{\circ}$ 81, 167-178.

WICKHAM, J.D., RIITTERS, K.H., WADE, T.G.W., VOGT, P. (2010): “A national assessment of green infrastructure and change for the conterminous United States using morphological image processing”. Landscape and Urban Planning, $\mathrm{n}^{\circ}$ 94, 186-195. 
